\title{
La situación del patrimonio industrial en España y Andalucía en 2009: retos y propuestas
}

Del 25 al 28 de febrero de 2009 se celebró en Ferrol (Galicia) el V Congreso TICCIH-España. A pesar de que el reconocimiento del patrimonio industrial como bien cultural es un hecho, las conclusiones de la reunión observan la necesidad de reformular el marco teórico, y de elaborar manuales de buenas prácticas. El reciente caso del desalojo en Sevilla del Colectivo Social "CSOA Fábrica de Sombreros" pone de manifiesto la necesidad de establecer unas nuevas políticas que recojan mejoras y reformas, tanto a nivel nacional como internacional, en el ámbito del patrimonio industrial.

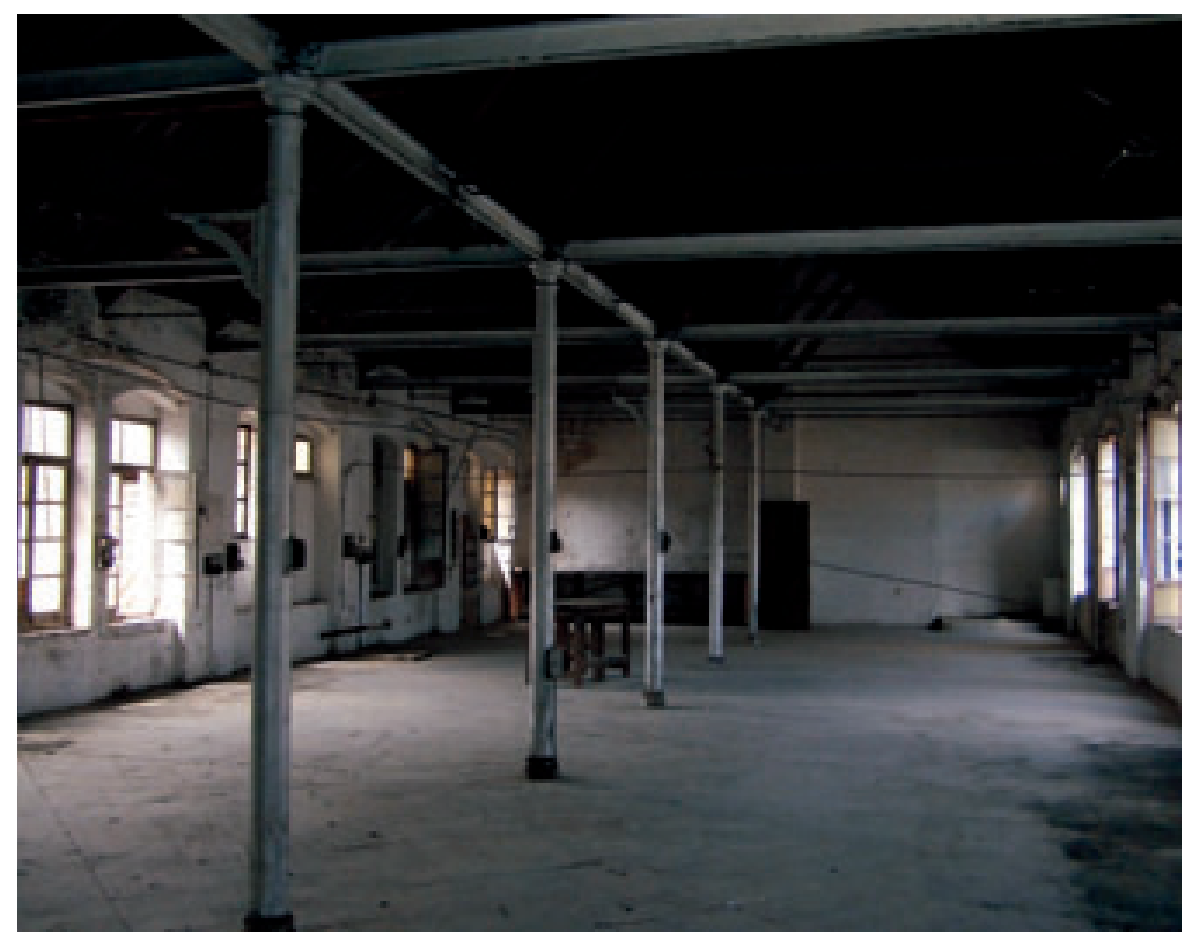

Interior de la Fábrica de sombreros. Mayo 2009. Días previos al desalojo. Foto: LaFundició

Tras el debate abierto en el V Congreso TIC$\mathrm{ClH}$-España y el contraste de las diferentes ponencias y comunicaciones, que dieron lugar a un conocimiento del estado de la cuestión del patrimonio industrial en España, la Junta Directiva de TICCIH-España hizo públicas las siguientes conclusiones:

- Fomentar la elaboración de inventarios y catálogos de patrimonio industrial como herramientas de gestión, con criterios de valorización de los elementos patrimoniales, alentando a las comunidades autónomas que aún carecen de éstos para que pongan en marcha proyectos conducentes a su rea- tarios se tengan en cuenta unos criterios mínimos de homogeneidad. Sería deseable la participación del Ministerio de Cultura, IPCE, en esa labor, valorando la posibilidad de unir en red los diferentes inventarios y haciendo visible un inventario del patrimonio industrial de España que con criterios y metodología homogénea sea expresión de los testimonios físicos que perviven de la historia industrial del país.

- Necesidad de que las administraciones públicas apliquen las leyes de protección del patrimonio a los elementos industriales y de la obra pública sobre los que tienen competencias. Necesidad de coordinación entre los diferentes niveles de la Administración: departamentos, consejerías o ministerios, por ejemplo el de Medio Ambiente o Industria, a fin de evitar decisiones contradictorias en relación al patrimonio industrial.

- Importancia de la profesionalización y de la elaboración de documentos teóricos relativos a la protección, conservación y rehabilitación (intervención) del patrimonio industrial asi como del paisaje cultural, en el que se engloba el industrial.

- Necesidad de incentivar y sistematizar el papel de la Universidad en el estudio del patrimonio industrial, desarrollando programas de formación específicos y potenciando la creación de grupos de investigación que realicen trabajos científicos que incorporen visiones globales y estudios comparativos a nivel internacional.

- Incluir la dimensión social del mundo del trabajo en la interpretación del patrimonio industrial e insistir en la dignidad de sus protagonistas, resaltando la importancia de una metodología integral para el análisis de la cultura del trabajo encarnada en el patrimonio industrial.

- Favorecer la participación e identificación de la población en la preservación del patrimonio industrial, promoviendo la difusión y el conocimiento de los valores de este patrimonio entre la población, y el acceso público al mismo.

- Manifestar el compromiso de TICCIHEspaña con el Convenio Europeo del Paisaje, ratificado por España en noviembre de 2007 y con entrada en vigor el 1 de marzo de 2008. Es necesario entender el paisaje como valor colectivo y patrimonio de todos, contemplando el concepto de paisaje en sentido amplio como sintesis de los procesos naturales y antrópicos.

- Definir un marco conceptual y continuar desarrollando metodologías, instrumentos y figuras de intervención especificos que aborden la rica complejidad de los paisajes 


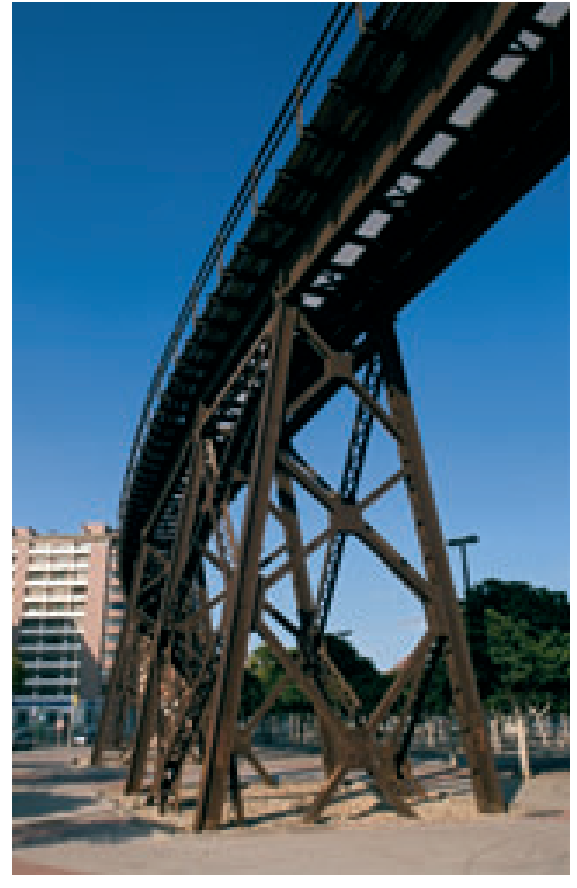

Cargadero de mineral El Alquife. Almería. Foto: Juan Carlos Cazalla, IAPH

culturales y las intervenciones en los mismos. Reivindicar la patrimonialización del paisaje cultural para alcanzar un reconocimiento equivalente al que se ha logrado para el patrimonio natural. Incluso, habria que dar un paso más y situar los recursos culturales ligados a la industria como elementos significativos en los planes urbanísticos y territoriales ya que en algunas ocasiones son el eje vertebrador del territorio.

- Necesidad de la realización de un estudio sobre los bienes muebles existentes en las colecciones públicas y favorecer la visibilidad de los pertenecientes a colecciones privadas. Fomentar la preservación in situ de los bienes muebles, por cuanto su descontextualización reduce su percepción como bien patrimonial.

- Solicitar a las instituciones relacionadas con la conservación del patrimonio una política de adquisiciones de bienes muebles industriales que den preferencia a: - Los bienes pensados en nuestro país. - Los bienes fabricados en nuestro país pero no inventados.

- Los bienes utilizados en el país y que constituyan parte del mundo material de la sociedad en cierto momento.
- Los bienes no utilizados en el país pero que son hitos técnicos.

- Los bienes no productivos relacionados con el entorno del mundo del trabajo.

- Exigir buenas prácticas en la restauración de los bienes inmuebles y muebles vinculados al patrimonio industrial, teniendo en cuenta los valores históricos, simbólicos, sociales, culturales... que los elementos industriales poseen. Cualquier intervención no puede menoscabar estos valores y debe estar respaldada por un estudio metodológico específico, tal y como ya sucede con el patrimonio histórico artístico.

Respecto de la importancia del patrimonio industrial andaluz hemos de destacar que su conocimiento nos aproxima de una manera eficaz a valorar patrimonialmente la trascendencia de una gigantesca transformación, la industrialización andaluza, que hoy es mejor conocida gracias a la labor desarrollada por nuestras universidades y grupos de investigación, por las asociaciones implicadas en su estudio y defensa y por la labor de la Consejeria de Cultura. Gracias a este intenso esfuerzo de investigación, reivindicaciones, protección y puesta en valor sabemos que en nuestra tierra se llevó a cabo un proce-

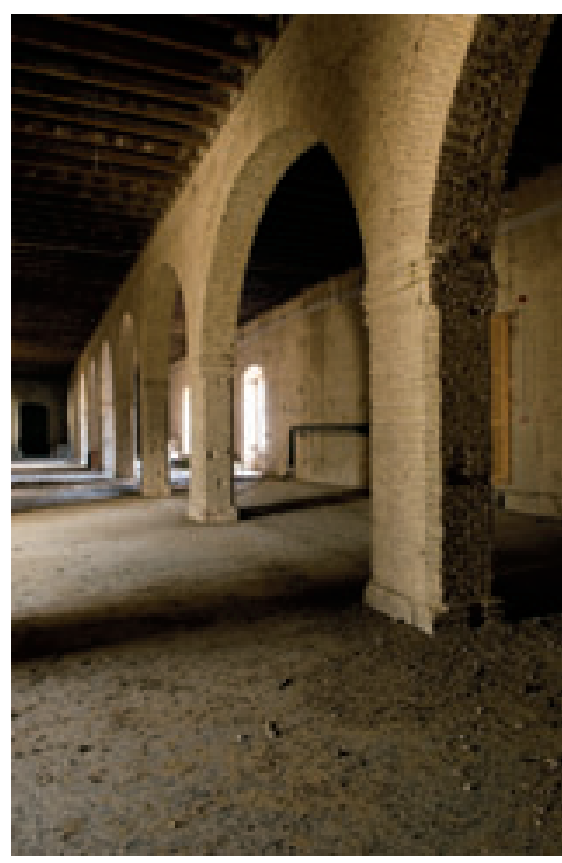

Atarazanas Reales. Sevilla. Foto: Juan Carlos Cazalla, IAPH
¿Por qué la herencia industrial es también parte integral del patrimonio cultural?

so histórico industrial desigual en cuanto a sus ritmos, su implantación territorial, sus consecuencias sociales y sus logros tecnológicos. Pero que, al mismo tiempo, y paradójicamente, se llevó a cabo un programa sin precedentes en torno a la creación de un mercado regional con importantes conexiones exteriores, una transformación significativa de las principales estructuras productivas y un cambio radical en los modos de vida y comportamiento de nuestra sociedad. Hechos que, a través de sus paisajes, arquitecturas, maquinas, instalaciones, archivos y referencias simbólicas, nos han legado, en sus formas materiales e inmateriales, un importantísimo sistema patrimonial que denominamos patrimonio industrial.

Las diferentes revoluciones industriales que se han producido desde finales del siglo XVIII han tenido un claro impacto en Andalucia, permitiendo que se estableciera un modelo singular de industrialización, con luces y sombras, pero en el que podemos descubrir en primer lugar nuestra memoria histórica tal como es, forjada en grandes líneas de continuidad espacio-temporales como las representadas por la minerometalurgia, la producción agroalimentaria, las industrias de la construcción naval, la pesca y las conservas, de los bienes de consumo, de la energía y del agua y de las infraestructuras y los transportes. Todo ello junto a claras debilidades, como fueron la insuficiente articulación territorial mediante una red de transportes eficiente, la escasa relevancia del sector financiero andaluz plasmado en instituciones operativas y la escasez de instituciones formativas destinadas a la investigación y la tecnología.

Pero, ¿qué hacer con los testimonios de ese pasado de luces y sombras? ¿Los perdemos para siempre? ¿Intentamos que se transfor- 


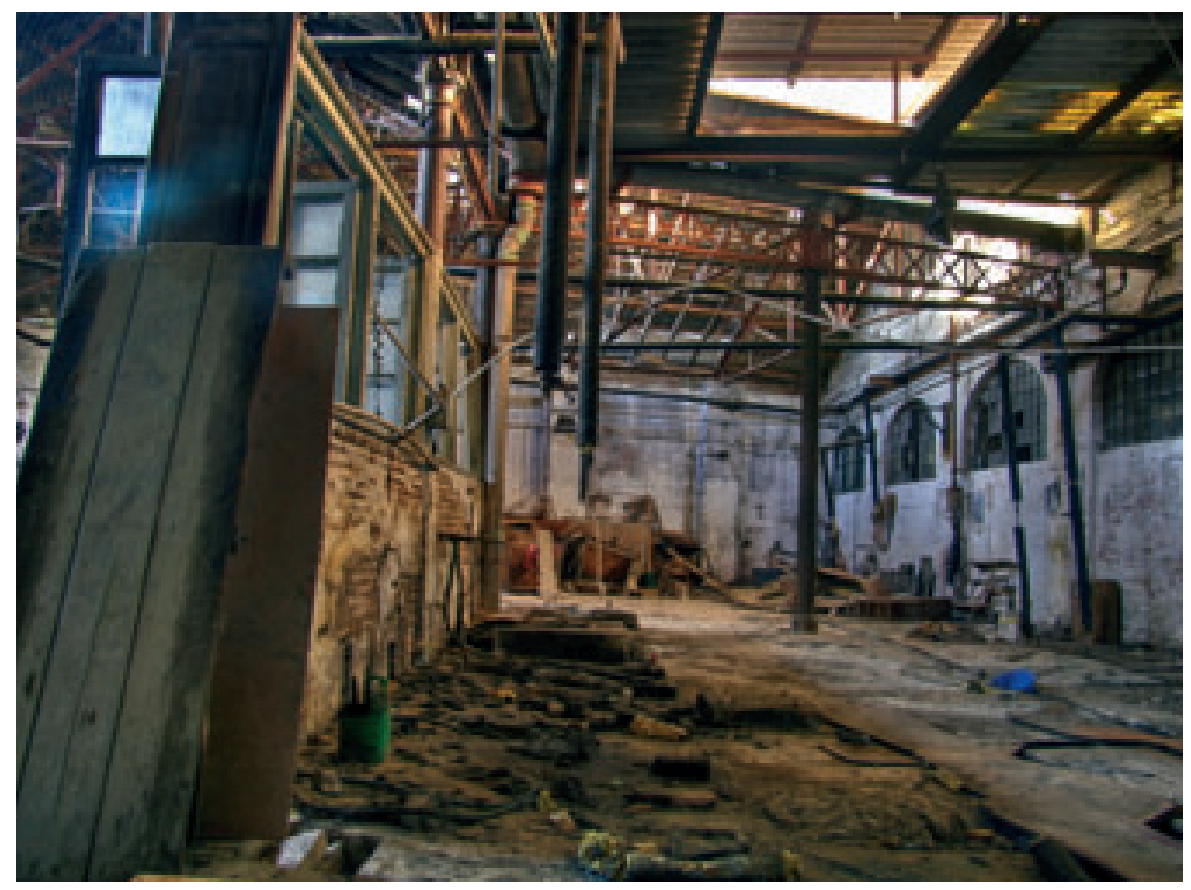

Hay que favorecer

la participación de

la población en la

preservación del

patrimonio industrial

Aspecto de abandono de la Fábrica de sombreros antes de su ocupación. Agosto 2008.

Foto: Salvador González-Barba Capote

men en una herramienta de conocimiento y en un factor de desarrollo? Para ello hemos de responder a las siguientes preguntas ¿Por qué la herencia industrial es también parte integral del patrimonio cultural? ¿Cuáles son los testimonios significativos del pasado industrial? ¿Cómo fueron los paisajes de la industrialización andaluza? ¿Cómo se pueden conservar las arquitecturas y la maquinaria? ¿Puede conservarse el legado inmaterial? ¿Cómo incrementar la protección del patrimonio industrial? ¿De qué manera han de ser rehabilitadas estas arquitecturas singulares con sus materiales industriales como el hormigón, el vidrio y el hierro y sus espacios gigantescos? ¿Cómo dotarnos de una museografía apropiada? En fin, muchí-

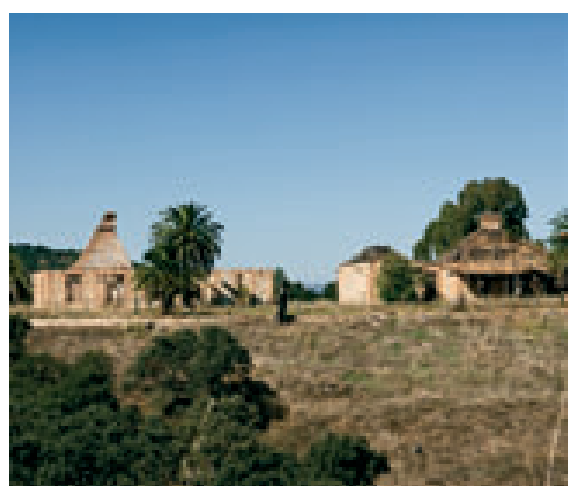

Cerro del Hierro. San Nicolás del Puerto. Sevilla. Foto: Juan Carlos Cazalla, IAPH simas preguntas que están pendientes de las respuestas adecuadas.

La fragilidad de este patrimonio, las amenazas a las que está sometido, su dispersión por el extenso territorio andaluz, la escasa percepción ciudadana de sus valores, hacen que sea urgente la tarea de acometer una Estrategia Andaluza de Patrimonio Industrial mediante un Plan Integral de Patrimonio Industrial que, tal como aparece reflejado en el Borrador que entregamos a la Consejera de Cultura en julio de 2008, nos conduzca, a partir de la inclusión en 2007 del patrimonio industrial en la nueva Ley de Patrimonio Histórico de Andalucia, en una Comunidad Autónoma plenamente avanzada en la protección plural e integral de su patrimonio cultural.

Esta propuesta tiene como objetivo principal el establecimiento de un Marco Estratégico:

- De conocimiento

- De conservación

- De protección

- De difusión

- De intervención

- De transferencia
En estos momentos de crisis y dificultades, nuestra propuesta avanza por el camino marcado por las políticas de la Segunda Modernización consistente en la coordinación, la transversalidad, agilidad, eficacia y rentabilidad.

Para que el patrimonio industrial de la Comunidad Autónoma de Andalucía no desaparezca de manera irreversible reiteramos la urgencia que tiene actualmente la búsqueda de propuestas y soluciones para que un sistema patrimonial tan significativo y relevante como es el compuesto por los testimonios históricos de la Cultura del Trabajo, que tanta trascendencia ha tenido y tiene para la Comunidad Autónoma andaluza, no se pierda irremediablemente. El reciente caso del desalojo en Sevilla del Colectivo Social "CSOA Fábrica de Sombreros" pone de manifiesto la necesidad de establecer unas nuevas políticas patrimoniales que conduzcan a que las administraciones públicas recojan las mejoras y reformas que la experiencia o la teoría vienen consolidando, tanto a nivel nacional como internacional, en el ámbito del patrimonio industrial.

\section{Julián Sobrino Simal}

Vicepresidente de TICCIH-ESPAÑA 